\title{
The Improvement of Polymer Structure Related to Radical Treatment of Alveolar Abcesses
}

\author{
CRISTIAN CONSTANTIN BUDACU ${ }^{1}$, MAGDA-ECATERINA ANTOHE ${ }^{1 *}$, \\ VICTOR COSTAN ${ }^{1 *}$, GHEORGHE RAFTU ${ }^{2 *}$, GABRIELA GURAU ${ }^{3 *}$, \\ LILIANA LACRAMIOARA PAVEL ${ }^{3 *}$, VICTORITA STEFANESCU ${ }^{3}$ \\ 1 "Grigore T.Popa" University of Medecine and Pharmacy, Faculty of Dental Medecine, 16 Universitatii Str., 700115, Iasi, Romania \\ ${ }^{2}$ Ovidius University Constanta, Faculty of Dental Medicine, 7 Ilarie Voronca Str., Constanta Romania \\ „3,Dunarea de Jos" University of Galati, Faculty of Medicine and Pharmacy, 47 Domneasca Str., Galati, Romania
}

Abstract. Painful periapical manifestations are inflammatory responses of periapical connective tissue to pulpal irritants, when the exudative forces become hyperactive. From the point of view of tooth preservation, apical resection is a valuable procedure in avoiding early edentation, as it is a factual surgical method that comes to aid the conservative endodontic therapy. Polymers are chemical compounds (in most cases organic) with large molecules (macromolecules) obtained from the union of a molecular chain (catena) of a large number of monomers usually with identical structural units. In our research we evaluated the resistance to traction 9 test specimens for which the structure was aimed at the improvement of the self-polymerizable acrylic structure by adding sodium maleate co-polymers, namely maleic anhydride, whose structure was linked to the anti-microbial substances, of the thymol type with controlled release, versions with greater resistance, they found clinical applicability on 244 cases. An increased resistance to fracture was registered for the test specimens II, which unites polymer powder together with the sodium maleate co-polymer, in a ratio of 3 to $1\left(F=1030\right.$ and $\left.\sigma_{\max }=37.73\right)$, test specimen III, which unites polymer powder together with the co-anhydride maleic polymer, in a ratio of 3 to $1\left(F=950\right.$ and $\left.\sigma_{\max }=37.88\right)$, followed by the same combinations to which it was added the care antibacterial substance, thymol. An important role in the long term in the success of the apical resection, in addition to the applied surgical technique, accrues to the retrograde obturation material, which insures an optimal healing at the peri-apical level insuring the bony apposition at this level.

Keywords: Periapical manifestations, apical resection, polymers, biomedical applications, copolymers.

\section{Introduction}

The apical resection, being among the main conservative surgical procedures has been and is learned and applied by all the dental schools in the world. The actual intervention consists in sectioning the spot without the tooth extraction[1-3].

In order to establish the diagnosis of a periapical disorder, the extra and intraoral examination must be performed in a precise and orderly manner. Establishing a methodical approach will lead to expeditious identification of the relevant aspects in the diagnostic process.

The procurement of diagnostic data are: interrogation - obtaining anamnestic data; clinical examination; and paraclinical examinations $\rightarrow$ radiological evaluation, microbiological examination, anatomopathological examination. Establishing the diagnosis $\rightarrow$ endodontic disease, periapical affectation, differential diagnosis[4-6].

Reasons for presentation: the patient complains of feeling of weight at the level of the tooth, pain with tiredness after mastication, pain with a neuralgiform character.

\footnotetext{
*email:magda.antohe@yahoo.com;victorcostan@gmail.com;gheorgheraftu@yahoo.com,gabriela.gurau@ugal.ro, doctorpavel2012@yahoo.com
} 
From the point of view of the differential diagnosis, a complete evaluation of the medical history can facilitate the identification of the etiological factors involved. Each stimulus used in the diagnostic tests must be standardized regarding the duration, the degree and the way of communicating the response to the stimulus

In the case in which carrying out the apical resection with retrograde obturation, after the resection it is obtained an inclined surface, it is localised the orifice of the channel with a drill no. 17, the cavity is adequately prepared, then the obturation material is applied, which in the past was represented by amalgam, currently of various types of auto-polymerizable acrylate, glass ionomers, poly-carboxylic cements.

The apical resection consists of the removal of the root apex and the periapical pathological process, concomitant or preceded by the correct endodontic treatment and the ideal obturation of the root canal. Apical resection is very often the only method that can prevent tooth extraction, allowing proper endodontic filling, removing the apex and periapical lesions, creating favorable conditions for bone tissue restoration[7-9].

The indications of the apical resection are given by 4 large groups of lesions: apical periodontal lesions; obstacles that prevent channel treatment; failure of endodontic treatment; radicular traumatic injury.

If endodontic improvement is impossible, the incision is made first in the abscess phase, and then the intervention, in the stabilization phase of the process, which corresponds to the principles of general surgery always, principles valid even today in the era of antibiotics.

After apical resection, the operated root must maintain a bone implantation equal to two thirds or at least half its initial length.

The incision is made under good illumination, and must be clean, comprising for the first time the mucosa and the periosteum using scalpel no. 10, 11 or 15 . It is specified that the type of incision must be appropriate to the operating tooth and to the respective clinical situation. A preference was found for the type of Pichler incision, followed closely by the trapezoidal incision[10-12].

In dentistry, dental materials are used both for the restoration of coronary lesions with a lack of substance (cavities, traumas, anomalies of form, volume), as well as auxiliary material. These materials can enter the composition of various obturations or prosthetic restorations.

Currently, polymeric materials occupy a very important place, in all areas of human activity. Polymeric biomaterials - simple or composite - are a very current topic and with a special dynamic, given the diversity of needs in the medical or pharmaceutical field[13-15].

At present, the quality of implants and devices for minimally invasive analysis of the body is sought to be improved, the biocompatibility and corrosion resistance of the materials to come into direct contact with the biological tissues improved, the development of efficient vector systems that will lead to the target organ different biological-active principle, the improvement of the systems of controlled release of drugs in the body.

The assimilation of synthetic macromolecular compounds in medicine and therapeutics, interdisciplinary fields, must answer the complexity of the problems of use that result from the temporary or long-term contact of the polymeric materials with the tissues and biological substances. In this context, polymeric biomaterials are those polymers or polymeric composites certified as biocompatible in contact with biostructures[16,17].

Suggested polymers for biomedical uses must comply with a variety of requirements that arise either from their chemical and physical structure (physical, chemical and mechanical criteria) or from the physiological environment where they will be used (biological criterion).

The polymers are easy to process, have mechanical flexibility and tear resistance, can be obtained in different forms and with different properties, at a reasonable cost; are used in applications that are not subjected to strong mechanical stresses, such as supporting human body weight, because they have small tensile strength and Young's modulus small values, but they have the advantage that they can be deformed long before their rupture occurs. 
Chemist Hermann Staudinger first proposed the idea that polymers are long chains of atoms, held together by covalent bonds, which he called macromolecules. His work has expanded knowledge chemicals in the polymer, which as led to further development in the field of polymer chemistry, during which were invented many useful polymeric materials such as neoprene, nylon and polyesters[18].

According to the International Union of Pure and Applied Chemistry, the term macromolecule refers to individual molecular chains and belongs to the field of chemistry, and polymers are part of another category of materials, being studied by the physics of polymers.

The most significant amount of macromolecular compounds that are based on their main practical uses, is their great mechanical resistance at tensile, tear, bending, abrasion, scissoring, etc.

The nature of the monomer, the structure of the polymer, the degree of polymerization, the polymerization agents used, the type of polymerization are the main factors that determine the physicalmechanical properties of the synthetic polymerization. The diversity of the conditions under which polymers are obtained make the physical-mechanical properties, such as: tensile strength, bending, shock, plasticity, elasticity, property of forming films and yarns, electrical resistance, electrical resistance, electrolyte resistance, aging, etc., be different.

Polymerization is a chemical reaction whereby a compound called monomer $(\mathrm{M})$ is transformed into a polymer (macromolecular structure, $\mathrm{Mn}$ ), according to the scheme:

$$
\mathrm{nM} \rightarrow(\mathrm{Mn})
$$

where " $n$ "represents the degree of polymerization. As it can be seen, no other by-product results from the reaction, unlike the polycondensation reaction. Monomer $\mathrm{M}$ can be a single substance or more. If several types of monomers are used (note with $\mathrm{A}$ and $\mathrm{B}$ ), the reaction is referred to as copolymerization, and the resulting product is a copolymer. The reaction is carried out according to the general scheme:

$$
\mathrm{nxA}+\mathrm{nyB} \rightarrow(\mathrm{AxBy}) \mathrm{n}
$$

In this case, the molar ratio $\mathrm{x} / \mathrm{y}$ in which the two comonomers participate in the reaction is also taken into account. Copolymers are useful, having properties generally intermediate to pure polymers (An or Bn).

From a chemical point of view, the polymerization takes place in three stages: the initiation, development and stopping of the polymerization.

In the development stage, the multitude of free radicals, operated, is chained with great rapidity, resulting in macromolecular chains[19].

In the stopping phase the growth reaction ceases, because the number of free radicals has decreased completely. The polymerization reaction is an exothermic reaction, it releases a temperature whose value is $30-40{ }^{\circ} \mathrm{C}$. The temperature increases with the production rate of the reaction. This caloric energy is added to the heating temperature of the patterns. To understand the diagram of the thermal regime of polymerization the two numerical data are fundamental: temperature at which volatization occurs $\left(100.3^{\circ} \mathrm{C}\right)$; temperature value $\left(30-40^{\circ} \mathrm{C}\right)$ released by the polymerization reaction.

The polymerization is carried out in devices called polymerizers, which can act with dry or humid temperatures[20].

\section{Material and method}

The purpose of this study is that of optimising the structure of the current polymeric materials used in the retrograde filling of the cavities resulted following the apical resection, recognised for the biocompatibility degree via co-polymers addition, compounds which allow the link of the various groupings of the thymol type cu anti-bacterial effect, carrying out polymer systems with controlled release of antibacterial substances.

We created 9 test specimens made up of Aesthetic Blue Polymer self- polymerizable acrylate in whose structure we used various proportions two types of co-polymers synthetized at the "P. Poni" Macromolecular Chemical Institute of Iasi; for two of these being added also an anti-bacterial substance of the thymol type. 
For all the powder versions, the monomer was the same, represented by Candulor, complying with the polymer proportions, the monomer foreseen in the usage instructions for this biomaterial. The copolymers, recognised as structures with a high degree of bio-compatibility in the medical field, were represented by AM88 - anhydride maleic methyl methacrylate co-polymer and M 88 - Na maleate copolymer, methyl methacrylate (Figure 1).<smiles>CC(C)(C)CC1C2COC1OO2</smiles><smiles>COC(=O)C(C)(C)CCC(C(=O)O)C(C)C(=O)[O-]</smiles>

Figure 1. Chemical structure of co-polymers : AM88 - anhydride maleic methyl methacrylate co-polymer and M 88 - Na maleate co-polymer, methyl methacrylate

The ratios of the polymer powder combination with each of the 2 co-polymers varied from 1:1 to $3: 1$. The final structure of the two test specimens was the following, mentioning the fact that the changes were aimed at the composition of the polymeric powder, the monomer remaining the same: test specimen1: self- polymerizable acrylate; Test specimen 2:Acrylate-AM88:1:1; Test specimen 3:Acrylate-AM88:2:1; Test specimen 4 :Acrylate:AM88:3:1; Test specimen 5 Acrylate-AM88:3:1Thymol; Test specimen 6-Acrylate-M88:1:1; Test specimen 7: Acrylate-M88 :2:1; Test specimen 8: Acrylate-M88:3:1;Test specimen 9: Acrylate-M88:3:1-Thymol (Figure 2).

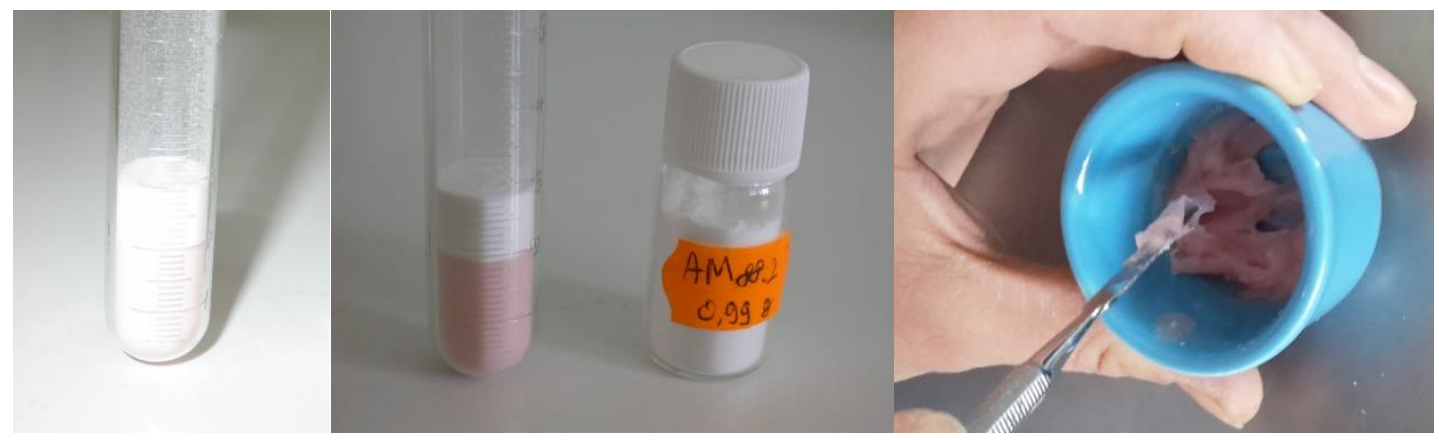

Figure 2. Aspects of the dosage of the polymer powder and preparation

The test specimens created in the same conditions and with the same dimensions (formed as rectangular plates with the longitudinal dimension of $40 \mathrm{~mm}$, length of approximately $20 \mathrm{~mm}$, having a $2 \mathrm{~mm}$ thickness) were submitted to the tensile forces at the machine of the Textenser type within the Polytechnic Institute of Iasi, Department of the Material Resistance. We carried out these tests because the co-polymers enhance the bio-compatibility degree of the polymers, yet it influences the biomechanical behaviour, aspect with negative consequences upon the resistance in time of the apical resection's results, these bio-materials representing an efficient protection barrier sufficient for the endodontic filling, biologically perfect for the peri-apical tissues (Figure 3). 


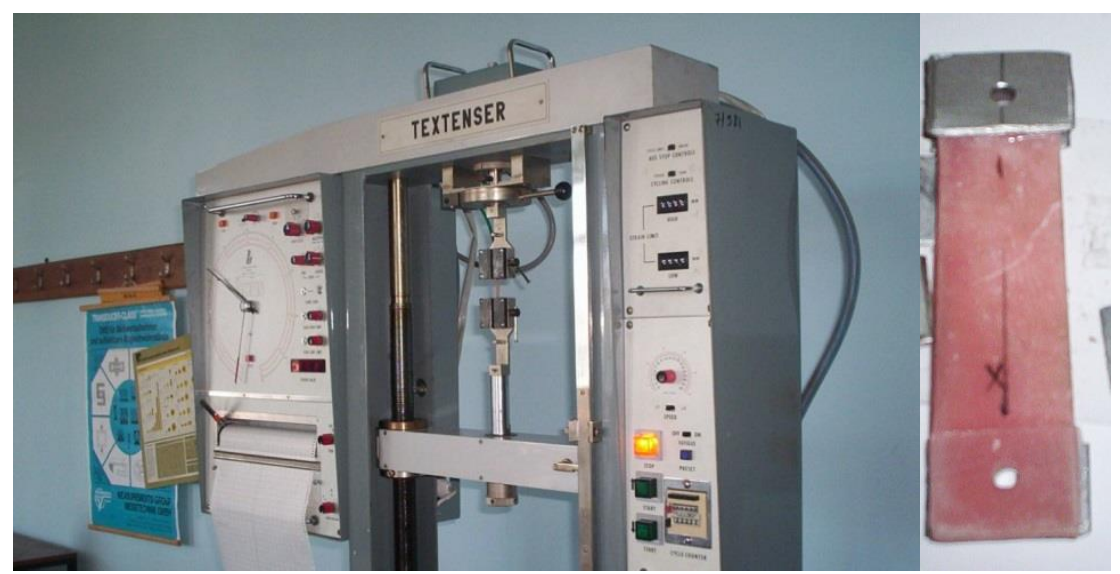

Figure 3. Trial Textener machine and test specimen

\section{Results and discussions}

After carrying out the biomechanical behaviour of the created test specimens it was recorded various values regarding the maximum force at which it took place the breaking of the test specimen; namely the maximum tension corresponding to the section in which the breaking took place.

The chemical structure differences of the 2 co-polymers are visible also within the biomechanical behaviour. The co-polymer based on the sodium maleate offers elasticity, which has as result the fracturing of the test specimen at a force much higher than the acrylate powder combinations with the other copolymer, namely maleic anhydride (Figure 4).

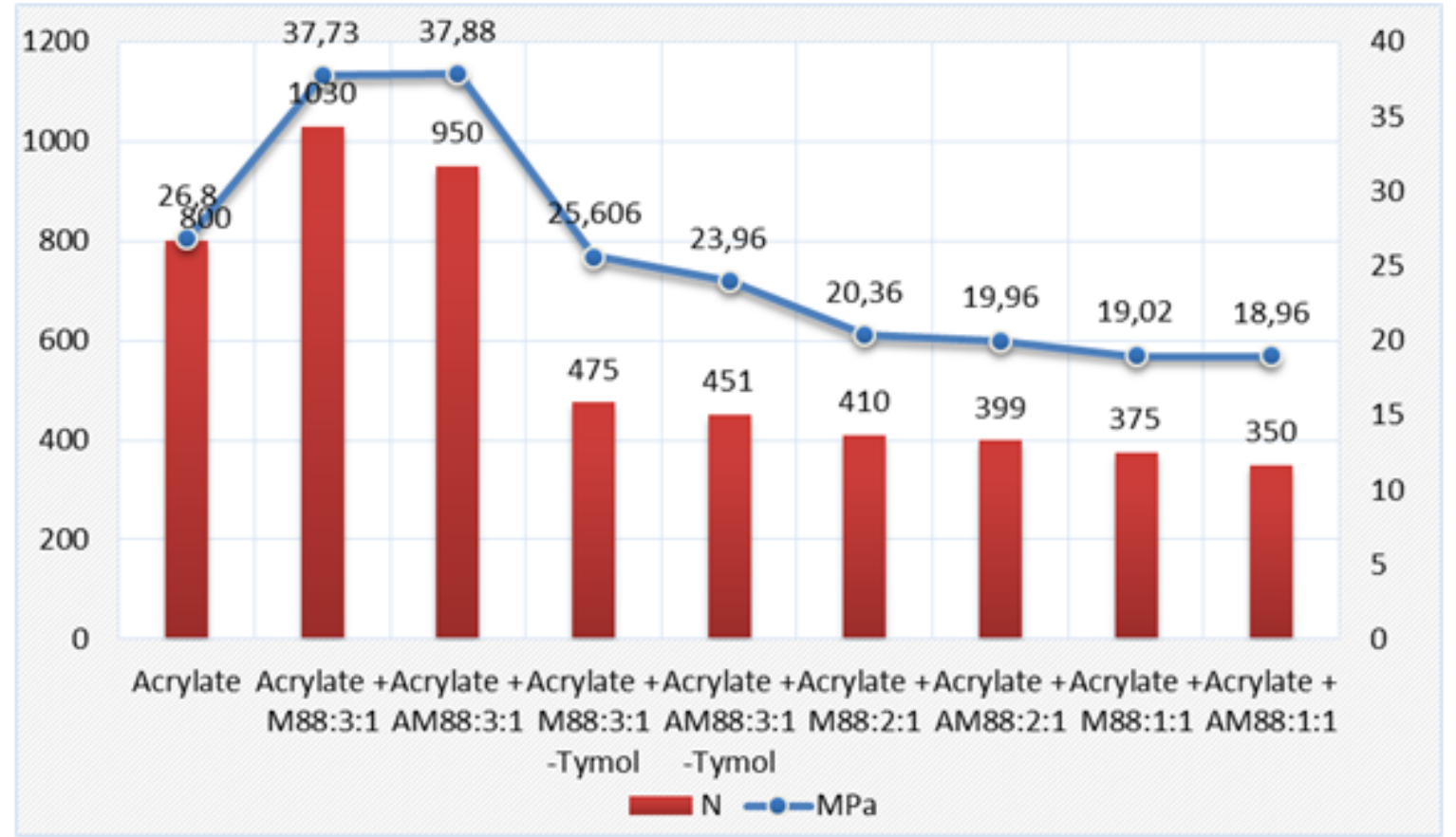

Figure 4. Results after having submitted the test specimens to the tensile forces

Thus the fracture at high forces was recorded for the test specimen II, which reunites the polymer powder in combination with the Sodium maleate co-polymer, in a ratio 3 to $1\left(\mathrm{~F}=1030\right.$ and $\left.\sigma_{\max }=37.73\right)$, test specimen III, which reunites the polymer powder in combination with the maleic anhydride copolymer, in a ratio 3 to $1\left(\mathrm{~F}=950\right.$ and $\left.\sigma_{\max }=37.88\right)$, followed by the same combination to which it was added an anti-bacterial substance, thymol. The higher the co-polymer ratio, the higher the biocompatibility degree, but the lower the resistance. 
In our research, we considered patients who were submitted to the apical resection intervention during the period 2017-2019, totalling 244 de patients - $54 \%$ women and $46 \%$ men, to whom it was applied also the retrograde obturation of the polymeric compositions with the 2 polymers, in a ratio 3 to 1 , as well as the same combinations which it was added thymol.

From the interventions performed, it is quite clear that the diagnosis that represents the overwhelming majority of the indications of apical resection is represented by the chronic periapical osteitis. This diagnosis is followed at a great distance by granulomas and cysts, as dental pathology. The other diagnosis are the numbers very low, being practical exceptions.

It is obvious that the major indication of apical resection is found in the group of frontal teeth, especially in the central incisors. These teeth, due to the characteristics of the endodontics, are very suitable for conservative endodontic treatment.

The need for surgery is probably the consequence of a failure of conservative treatment, of a technical error, or of the convenience of the practitioner who prefers to resort to surgery before even attempting a conservative treatment. The largest intervention was performed both at the maxilla and at the mandible by the interventions at the level of the central incisors, followed by the lateral and canine ones. The apical resection is practiced more frequently in the maxillary premolars than in the mandibular ones, in the molars, regardless of the arch, the procedure is highly indicated.

Regarding the type of incision, we know very well that the operation as such depends very much (visibility in the operative field, bleeding, possibilities of suturing, healing of the mucosal wound). It is specified that the type of incision must be appropriate to the operating tooth and to the respective clinical situation.

Very good results were observed for the association of the Pichler incision type with obturation material at the retrograde level: acrylate $+\mathrm{M} 88+$ thymol $(42 \%)$, followed close by the trapezoid incision associated with acrylate +AM88 (36\%). In the long run, the check-up X rays carried out after 1 year after carrying out the resection very good results were recorded regarding the reconfiguration of the periapical space for the efficient healing in case of the retrograde obturation in whose structure it was found the sodium maleate and thymol(Fig.5).

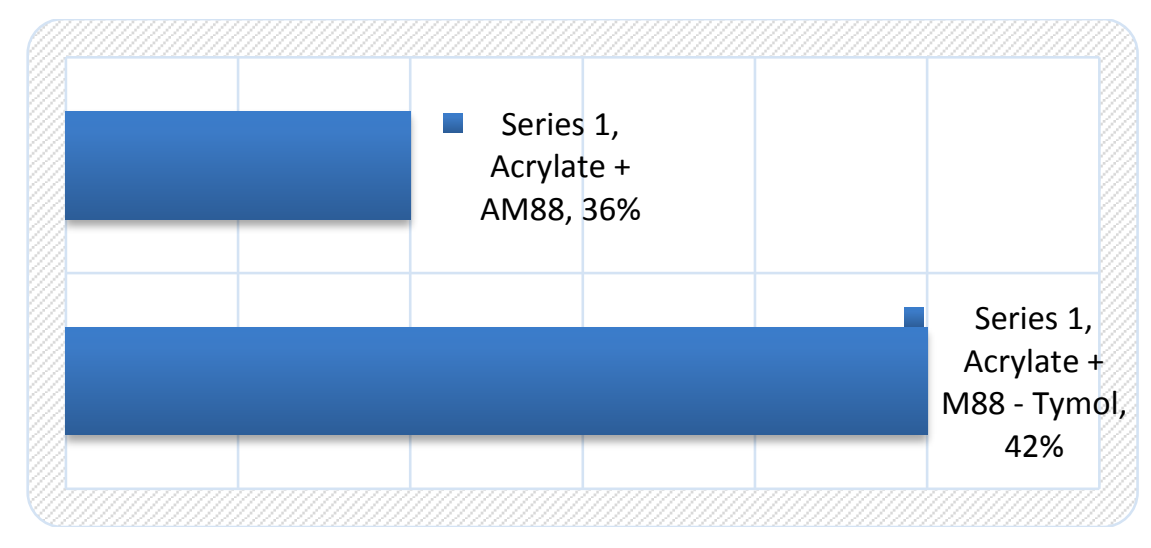

Figure 5. Clinical application aspects of the retrograde fillings in the case of the apical resections

From the endodontic perspective, periapical surgery is only indicated when a good quality treatment has been tried, but it could not be completed, or if there was no cure after treatment.

Periapical radiotransparencies, detected before or after the completion of endothelial therapy, are the most common indications of periapical surgery and are mostly represented by the periapical granuloma. Because the main cause of periapical inflammation is endodontic in nature, surgical treatment cannot be considered as the first choice because it does not debridement the root canal, as endodontic therapy does. Periapical surgery should never be performed before conventional nonsurgical canal treatment has been performed. 
In practice, however, for many reasons, this interpretation is not always true because factors such as cost, type of health insurance, operator skill and duration of treatment can play an important role.

\section{Conclusions}

The apical resection is a surgical intervention that removes the apex part of the root, along with the pathological elements around it. It aims to remove the apical and periapical pathological focal point, in order to make it possible a correct obturation of the root canal.

The improvement of the retrograde obturation of acrylate auto-polymerizable by adding co-polymers based sodium maleate, namely maleic anhydride, with controlled release of antibacterial substances of the thymol type lead to an optimal peri-apical healing post-resection.

The operation is life-saving when other conservative treatment methods have failed to cure periapical lesions.

\section{References}

1. IMAI, Y., SATO, T., MORI, S., OKAMOTO, M., A histomorphometric analysis of bone dynamics in denture supporting tissue under continuous pressure. J Oral Rehab, 2002; 29: 7279.

2.OWALL, B., BUDTZ-JÖRGENSEN, E., et al, Removable partial denture design: A need to focus on hygienic principles? Int J Prosthodont 15:371-78, 2002.

3.ANDREI, M., DINISCHIOTU, A., DIDILESCU, A.C., IONITA, D., DEMETRESCU, I., Periodontal materials and cell biology for guided tissue and bone regeneration. Annals of Anatomy-Anatomischer Anzeiger.2018 Mar 1;216:164-9.

4.NIKOLIDAKIS, D., JANSEN, J.A., The biology of platelet-rich plasma and its application in oral surgery:literature review. Tissue Engineering Part B: Reviews. 2008 Sep 1;14(3):249-58.

5.SALMON, C.R., GIORGETTI, A.P., LEME, A.F., DOMINGUES, R.R., KOLLI, T.N., FOSTER, B.L., NOCITI Jr, F.H., Microproteome of dentoalveolar tissues. Bone. 2017 Aug 1;101:219-29.

6.BABAJI, P., DEVANNA, R., JAGTAP, K., CHAURASIA, V.R., JERRY, J.J., CHOUDHURY BK, DUHAN D. The cell biology and role of resorptive cells in diseases: a review. Annals of African medicine. 2017.Apr;16(2):39.

7.EARAR, K; BICA, C.; CERGHIZAN, D.; et al. ,The Role of Functional Polymers in the Optimization of the Acrylic Biomaterials Used in Removable Prosthetic Restoration III. Behaviour of the adhesive used for the multilayer consolidation, Mat.Plast. , 53, (3), 2016, 512-517

8.ENISLIDIS, G., WITTWER, G., EWERS, R.: Preliminary Report on a Staged Ridge Splitting Technique For Implant Placement in the Mandible: A Technical Note. Int. J. Maxillofac. Implants, MayJun. 2006, 21: $445-449$..

9.SAVEANU, C.I., DRAGOS, O., DANILA, V., Ultrastructural analysis by scanning electron microscopy of dental structures conditioning with ortophosphoric acid and ER.CR:YSGG Laser Irradiation, Rev.Chim., 68, (1), 2017, 48-51

10.ELIAN, N., JALBOUT, Z., EHNRLICH, B., CLASSI, A., AL-KAHTANI, F., FROUM, S., TARNOW, D.P.: A Two-Stage Full-Arch Ridge Expansion Technique: Review of the Literature and Clinical Guidelines. Implant Dentistry, Mar 2008, 17: 16 - 23.

11.JENSEN, O.T.: The Sinus Bone Graft. Second Edition, Denver, Colorado, Quintessence Publishing, 2007.

12.BUCUR, A., NAVARROVILA, C., LOWRY, J., ACERO, J.: Compendiu de Chirurgie Oro - Maxilo - Facială. vol. 1 and vol. 2, Q Med Publishing, 2009, Bucuresti. I : 223 - 228.

13.EARAR, K., GRADINARU,S., PARIZA,G., et al., Effect of the Sterilization Procedures of Different Surgical Meshes for Abdominal Surgery, Rev.Chim., 68, (8), 2017, 1868-1873

14.DIRTU, D., LUNGU, N.C., CHIRITA,P., et al., Synthesis of Novel 4-(3,5-Dibromo-2hydroxyphenyl)-5-Methyl-1,3-Dithiol-2-ylidene Derivatives, Rev.Chim., 67, (3), 2016, 534-537 
15.SAVEANU, C.I., DRAGOS, O., In vitro study of dentin hybrid layer of a new resin composite material:Comparison between the use of Diamond and ER,CR:YSGG Laser Cavity Preparation, Digest Journal of nanomaterials and biostructures, 7(4),2012, pg. 1473-1480

16.MURARIU, A., FORNA, AGOP, D., MANOLACHE, F., et al., Assessment of the oral health risk factors in young people, Romanian journal of oral rehabilitation , 9 ( 3) ,2017, Pg: 48-54 ;

17.PETERSON, E., HUPP,T: Contemporary Oral and Maxillofacial Surgery. Fourth Edition, Mosby, 2003.

18.MUNOZ-BONILlA, A., FERNANDEZ-GARCIA, M.: Polymeric materials with antimicrobial activity, In: Progress in Polymer Science 37 (2012), p. 281- 339

19.SATO, N., DDS: Chirurgie Parodontala. Atlas Clinic. Quintessence Publishing,2009.

20. WANG Y., TANG Y.L., ZHOU Z.J., JI E., LOPEZ G.P., CHI E.Y., SCHANZE K.S., WHITTEN D.G., Membrane perturbation activity of cationic phenylene ethynylene oligomers and polymers: selectivity against model bacterial and mammalian membranes, Langmuir (2010) 26, pp. 12509-12514.

Manuscript received: 4.03 .2020 